\title{
Letter from the Institute
}

It was more than 14 years ago that the Centre for the History of European Expansion started its publication of Itinerario. With this issue $(1991 / 1)$ the Institute for the History of European Expansion has started the 15th volume of the journal. All that time Dr. George Winius of the Department of History at Leiden University has helped to produce this publication, in the forefront as an editor for many years or in the background as a contributor, book reviewer and as an avid critic of errors both in typography as well as in the usage of English, his native tongue.

The present editors of Itinerario decided to honour the many contributions and good services of George Winius by publishing an interview with him. In addition, several short contributions are included which were presented at a small round table discussion some two years ago, held on the occasion of George's retirement from the Department of History. The contributions all deal with the differences between the Iberian expansion 'system' and that of the Northwest Europeans. This topic has dominated virtually all the scholarly publications of George Winius in which he aimed to explain the various aspects of Portuguese expansion overseas. That was a difficult task, since the non-specialists have usually much more knowledge of the non-Iberian expansion, which has been better studied and on which much more has been written in the current international languages.

George Winius, however, has earned himself an international reputation in the historical arena by insisting that the beginnings of European expansion cannot be understood without an intimate knowledge of the Portuguese initiatives in this process. His unique proze has helped to give this early Portuguese expansion the scholarly place it deserves. The present editors of Itinerario all hope that George will continue to write about European Expansion for a long time to come. Old soldiers and editors never die...

The Editors 


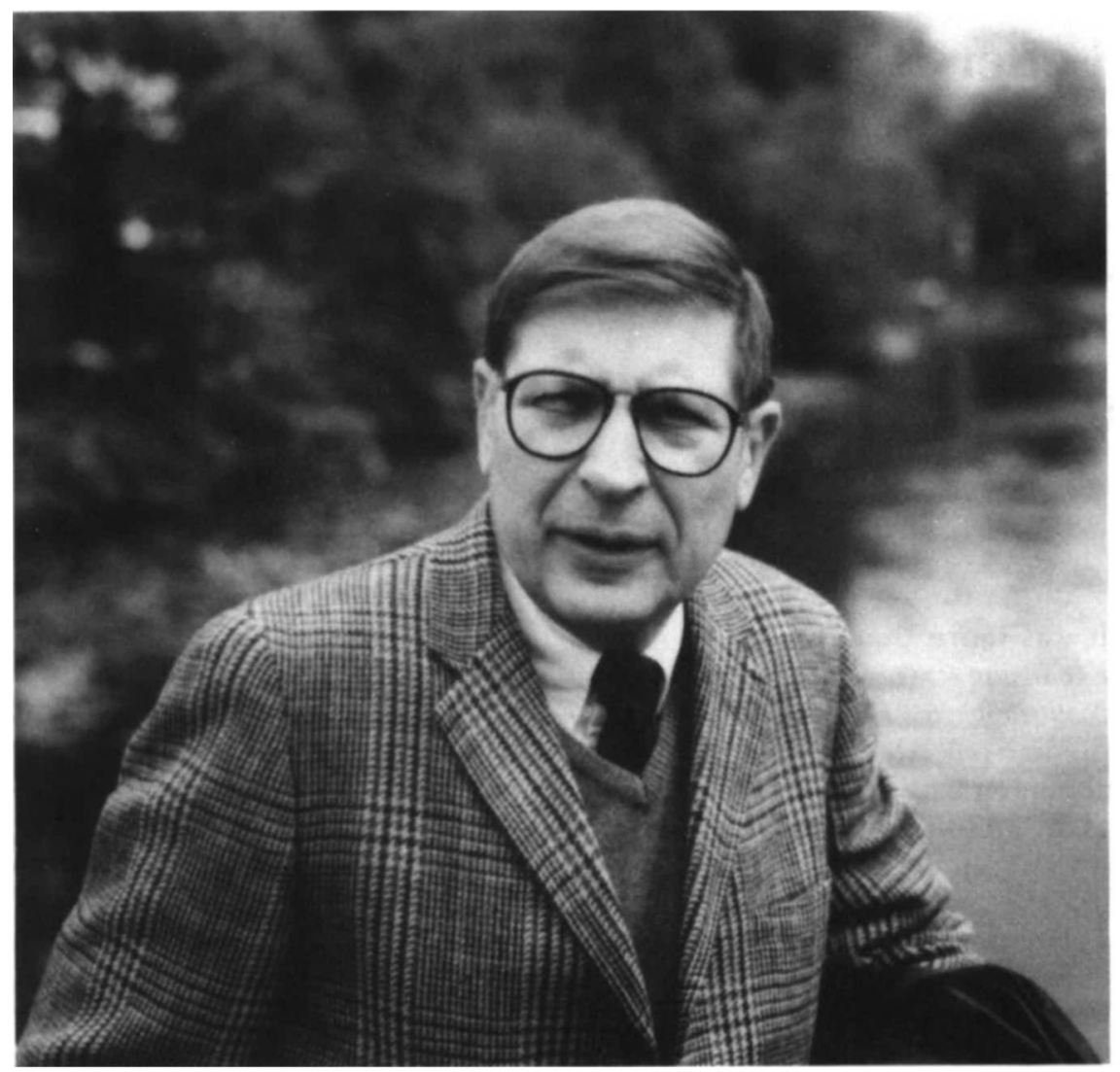

